\title{
Analisis dan Desain Sistem Informasi Geografis untuk Pemetaan Infrastruktur Pemerintahan (Studi Kasus: Kota Pontianak)
}

\author{
Dochi Ramadhani ${ }^{1}$, Ryan Permana ${ }^{2}$, Chandra Lesmana ${ }^{3}$
}

Program Studi Pendidikan Teknologi Informasi dan Komputer, Institut Keguruan dan Ilmu Pendidikan PGRI Pontianak, Indonesia

\author{
Keywords: \\ spatial data; \\ infrastructure; \\ governance; \\ geographic information systems; \\ planning;
}

maintenance

\section{ABSTRAK}

Abstract: The purpose of this research is to produce an application of geographic information system that can help Bappeda Pontianak City and other related parties in: 1) managing information of government infrastructure, 2) mapping the location of government infrastructure deployment, 3) handling historical data of government infrastructure, 4) provides information on the condition of government infrastructure so as to better support infrastructure maintenance planning and local revenue management. This research is done by storing the data attribute infrastructure into a tabular data, then mapping infrastructure based on the location where the infrastructure is built into a thematic layer. The thematic layers are then arranged overlaid with other layers and relate to tabular data so that it can be analyzed based on geographic conditions (spatial analysis) as well as analysis based on tabular data and client-server function so that the number of infrastructure points on the admin and user side amounts to same. The resulting system can handle the data input process and data search process and perform spatial functions well. The data input by the user is always validated and there is feedback to the user when an error occurs. The system is capable of handling historical data of an infrastructure based on the infrastructure point id and displaying it in the form of attribute data. The system can show the deployment of infrastructure in Pontianak City which is described in the form of maps so that users can know more clearly the location and condition of existing infrastructure. The results of research using blackbox testing by looking directly the results of existing applications.

Abstrak: Tujuan penelitian ini menghasilkan suatu aplikasi sistem informas geografis yang dapat membantu Bappeda Kota Pontianak dan pihak terkait lainnya dalam: 1) mengelola informasi infrastruktur pemerintahan, 2) memetakan lokasi penyebaran infrastruktur pemerintahan, 3) menangani data historis infrastruktur pemerintahan, serta 4) memberikan informasi tentang kondisi infrastruktur pemerintahan sehingga dapat mendukung perencanaan perawatan infrastruktur dan pengelolaan pendapatan daerah menjadi lebih baik. Penelitian ini dilakukan dengan menyimpan data-data atribut infrastruktur menjadi suatu data tabular, kemudian memetakan infrastruktur berdasarkan lokasi tempat infrastruktur dibangun ke dalam suatu layer tematik. Layer tematik tersebut kemudian disusun bertumpuk (overlay) dengan layer-layer lain serta direlasikan dengan data tabular sehingga dapat dilakukan analisis berdasarkan kondisi geografis (analisis spasial) maupun analisis berdasarkan data tabular dan fungsi client-server agar jumlah titik infrastruktur pada sisi admin dan pengguna berjumlah sama. Sistem yang dihasilkan dapat menangani proses input data dan proses pencarian data serta melakukan fungsi-fungsi spasial dengan baik. Input data oleh pengguna selalu divalidasi dan ada umpan balik kepada pengguna ketika terjadi kesalahan. Sistem mampu menangani data historis infrasruktur berdasarkan id titik infrastruktur dan menampilkannya dalam bentuk data atribut. Sistem dapat menampilkan penyebaran infrastruktur di kota Pontianak yang digambarkan dalam bentuk peta sehingga pengguna dapat mengetahui secara lebih jelas lokasi dan kondisi infrastruktur yang ada. Hasil penelitian menggunakan pengujian blackbox dengan melihat lansung hasil aplikasi yang ada.

Alamat Korespondensi:

E-mail: dochi@gmail.com (Dochi Ramadhani) 


\section{Pendahuluan}

Undang-undang No.22 Tahun 1999 tentang Pemerintahan Daerah Pasal 11 Ayat (2) menggariskan bahwa bidang pemerintahan yang wajib dilaksanakan untuk daerah kabupaten dan daerah kota mencakup semua kewenangan pemerintahan meliputi Pekerjaan Umum, Kesehatan, Pendidikan dan Kebudayaan, Pertanian, Kehutanan, Pertambangan, Perhubungan, Industri dan Perdagangan, Penanaman Modal, Lingkungan Hidup, Pertanahan, Koperasi dan Tenaga Kerja. Wewenang pemerintahan yang demikian luas memerlukan pengembangan kemampuan dan sarana yang memadai, meliputi perencanaan, pengorganisasian dan penjadwalan pelaksanaan, pemantauan dan pengendalian. Bidang-bidang kewenangan tersebut meliputi pembangunan fisik maupun non-fisik. Pembangunan fisik jelas mengandung implikasi keruangan, baik dalam arti ruang (lokasi, distribusi) maupun dampaknya.

Namun demikian, pembangunan non-fisik pun seperti misalnya pembangunan aspek kesehatan, memerlukan informasi tematik mengenai distribusi dan kepadatan penduduk, lokasi dan kemampuan fasilitas kesehatan dan sebagainya. Informasi yang meliputi tema apapun selalu diperlukan dalam, kaitan dengan lokasi atau distribusinya sebagai bahan kebijakan ataupun bahan perencanaan. Dapat dikatakan bahwa untuk dapat melaksanakan sebagian dari segenap wewenang sebagaimana digariskan dalam Undang-Undang No.22 tahun 1999, Pemerintahan Kabupaten dan Kota memerlukan informasi yang merujuk kepada lokasi atau peta. Dalam hubungan itu, survey dan pemetaan serta pemantauan sumberdaya alam dan lingkungan perlu diselenggarakan secara sistematik dan programatik.

Menurut Prahasta: 2002:35 Pada proses pembangunan peran peta ini sangat jelas, penggunaan peta meliputi ketiga aspek dalam urutan penanganan pembangunan yakni sebagai berikut.

1. Perencanaan dan Persiapan.

a. Pemilihan lahan.

b. Pengadaan lahan.

c. Penyiapan lahan.

2. Perancangan dan Konstruksi.

a. Rancangan lay-out.

b. Penjadwalan kegiatan.

c. Pemantauan konstruksi dan lain-lain.

3. Pengoperasian dan Pemeliharaan.

a. Pengelolaan aset.

b. Pengoperasian dan pengelolaan infrastruktur / utilitas.

c. Administrasi pajak tanah dan bangunan dan lain-lain.

Dari 3 aspek kegunaan peta di atas, terlihat bahwa peta yang diperlukan untuk pembangunan daerah dapat pula dimanfaatkan bagi pengoperasian dan pengelolaan banyak aspek lain, baik bagi pemeliharaan dan pengelolaan infrastruktur dan utilitas maupun dalam rangka pengelolaan penghasilan daerah. Diperlukan peta dasar yang baku sebagai sistem rujukan bagi segenap data/informasi yang diperlukan bagi penyelenggaraan fungsi-fungsi tersebut. Disamping peta dasar, peta tematik merupakan kelengkapan yang diperlukan bagi penanganan pembangunan.

Menurut Dulbahri, 1993:56 Untuk aspek kehutanan, aspek tematik ini menggambarkan karakteristik seperti jenis, luas, kondisi hutan. Untuk sektor pertanian menggambarkan jenis dan luas persawahan, jenis tanah, jenis dan kondisi sistem irigasi, dan sebagainya. Keterangan/ peta tematik ini diperlukan untuk segenap kenampakan lapangan (terrain features), seperti benda-benda alam maupun buatan, sumberdaya alam, kondisi masyarakat, lingkungan hidup, iklim dan cuaca, serta bagi segenap kejadian dan aktifitas.

Kota Pontianak merupakan salah satu daerah di Indonesia yang sedang berkembang dimana sedang terjadi pembangunan infrastruktur pemerintahan yang sangat cepat pada saat ini. Dalam waktu yang singkat, otonomi daerah dan pemekaran wilayah yang terjadi menyebabkan pembangunan infrastruktur pemerintahan yang sangat banyak. Akan tetapi pembangunan infratstruktur pemerintahan yang banyak tersebut tidak diimbangi dengan perawatan yang memadai.

Bambang Widianto, Ketua Asosiasi Perawatan Bangunan Indonesia (APBI) Kalimantan Barat menyampaikan bahwa paradigma penganggaran biaya perawatan atau pemeliharaan gedung pemerintah oleh pengambil kebijakan di tingkat Pemprov Kalbar maupun Kota Pontianak masih bersifat insidentil, bukan terprogram dan tidak berkala. Akibatnya, usia gedung menjadi semakin pendek dan biaya yang dikeluarkan untuk perawatan menjadi membengkak (Pontianak Post, 2008).

Infrastruktur pemerintahan di Kota Pontianak berjumlah kurang lebih 1100 dan tersebar secara geografis. Agar proses menentukan infrastruktur yang memerlukan perawatan lebih mudah, salah satu cara yang dapat digunakan 
adalah pemetaan. Dengan pemetaan, lokasi infrastruktur pemerintashan yang memerlukan perawatan dapat dilihat dengan jelas sehingga perawatan infrastruktur pemerintahan tersebut dapat ditentukan dengan lebih baik.

Infrastruktur pemerintahan dapat dipetakan dalam sebuah sistem informasi geografis. Sistem Informasi Geografis (SIG) adalah merupakan suatu sistem berbasiskan komputer yang digunakan untuk menyimpan dan memanipulasi informasiinformasi geografis. SIG dirancang untuk mengumpulkan, menyimpan dan menganalisis objek-objek dan fenomenafenomena dimana lokasi geografis merupakan karakteristik yang penting atau kritis untuk dianalisis. Dengan SIG, representasi maupun analisis spasial terhadap data-data infrastruktur pemerintahan yang ada dapat dilakukan, oleh karena itu perlu dikembangkan suatu sistem informasi geografis yang dapat memetakan lokasi infrastruktur pemerintahan dan mengelola data-data atribut infrastruktur pemerintahan tersebut sehingga perawatan infrastruktur pemerintahan kedepannya dapat diarahkan dengan lebih baik.

\section{Metode}

Metode penelitian yang digunakan dalam penelitian ini adalah sebagai berikut.

1. Perancangan aplikasi menggunakan metode blackbox dimana metode blackbox adalah perancangan aplikasi dan validasi aplikasi dengan melihat hasil aplikasi.

2. Data Flow Diagram (DFD), untuk menggambarkan aliran data pada sistem yang terdiri dari dua bagian utama yaitu sistem input data dan sistem analisis data.

3. Entity Relationship Diagram (ERD), untuk menjelaskan hubungan antardata dalam basis data berdasarkan objekobjek dasar data yang mempunyai hubungan antarrelasi.

Perangkat lunak yang digunakan dalam penelitian ini adalah sebagai berikut.

1. Sistem operasi Windows XP Service Pack 2.

2. Xampp 1.7.3

3. ArcView GIS 3.3, digunakan dalam mengolah data spasial.

4. Database MySQL 5.1.41

5. SUIPack 5.8 dan Raize Component.

6. MySQL Connector ODBC 3.51.20

7. Navicat Premium 9.03

8. Delphi 7 dan MapObject 2.2, digunakan untuk pengembangan system.

9. Garmin MapSource 6.15.7 digunakan untuk mengambil data hasil tracking dari GPS.

Perangkat keras yang digunakan dalam penelitian ini adalah:

1. PC/Laptop, digunakan untuk pengembangan system.

2. GPS, digunakan untuk menentukan lokasi Infrastruktur.

3. Kamera untuk dokumentasi keadaan bangunan atau infrastruktur.

4. Kabel LAN untuk uji coba jaringan lokal berbentuk kabel.

5. Wifi router untuk pengembangan aplikasi dalam uji coba jaringan wireless

Penelitian ini terdiri dari beberapa tahapan. Langkah-langkah penelitian yang dilakukan sebagai berikut:

1. Studi literaturn dilakukan guna memahami materi-materi yang berkaitan dari beberapa literatur.

2. Pengumpulan data dari BAPPEDA Kota Pontianak dengan melakukan wawancara dan observasi. $\backslash$

3. Perancangan desain antarmuka diawali dengan melakukan perancangan konseptual sistem yang dibangun, perancangan prototipe sistem, dan validasi sistem serta analisis hasil pengujian.

4. Analisis system dilakukan analisis terhadap sistem secara keseluruhan untuk memudahkan dalam melakukan penarikan kesimpulan.

5. Penarikan kesimpulan dirumuskan berdasarkan pengujian yang telah dilakukan apakah sistem yang dirancang mampu memberikan informasi tentang keadaan infrastruktur pemerintah yang ada berdasarkan klasifikasi infrastruktur yang telah ditentukan. 


\section{Hasil dan Pembahasan}

Sistem yang dibangun merupakan pusat pengiriman data dan visualisasi data dimana pada sistem ini terdiri dari ArcView, Delphi dan komponen MapObjects. Desain rancangan sistem yang dibangun ditunjukkan oleh gambar 1 berikut.

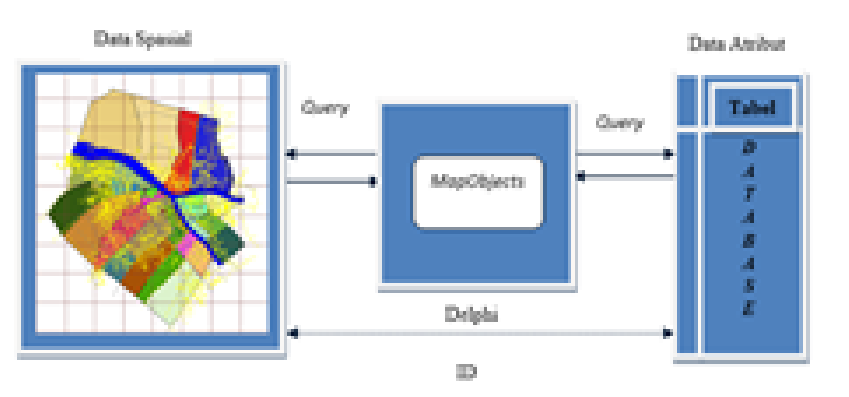

Gambar 1. Desain Sistem Informasi Geografis Insfrastruktur Pemerintahan Kota Pontianak

Entity Relational Diagram (ERD) merupakan gambaran hubungan antar-entitas yang dipergunakan dalam sistem. Perancangan ERD meliputi tahap penentuan entitas, penentuan relasi antar-entitas, tingkat relasi yang terjadi, dan konektivitas antar-entitas. Entitas-entitas yang ada pada sistem ini ada lima sebagai berikut:

1. Bangunan, yaitu infrastruktur pemerintah yang dibangun.

2. Instansi, yaitu lembaga yang memiliki infrastruktur yang terkait.

3. Kelurahan, yaitu wilayah dimana infrastruktur dibangunan.

4. Wilayah, yaitu daerah dimana infrastruktur dibangunan.

Relasi antara tiap-tiap entitas dapat dituliskan dalam enterprise rules. Pada sistem ini, banyak infrastruktur terletak di satu kelurahan dan satu kelurahan memiliki banyak infrastruktur. Banyak infrastruktur terletak di satu wilayah dan di satu wilayah dibangun banyak infrastruktur. Satu infrastruktur memiliki banyak histori dan banyak infrastruktur dibangun pada satu wilayah. Satu infrastruktur memiliki satu record keadaan.

Relasi-relasi dan konektivitas yang terjadi dari entitas-entitas yang ada adalah sebagai berikut.

1. Terletak.

Infrastruktur (M) terletak di wilayah (1).

Infrastruktur (M) terletak di kelurahan (1).

2. Memiliki.

Infrastruktur (1) memiliki histori(M).

Infrastruktur (1) memiliki keadaan(M).

Keterkaitan dan hubungan antar-entitas digambarkan melalui Diagram ER seperti terlihat pada gambar 2 berikut.

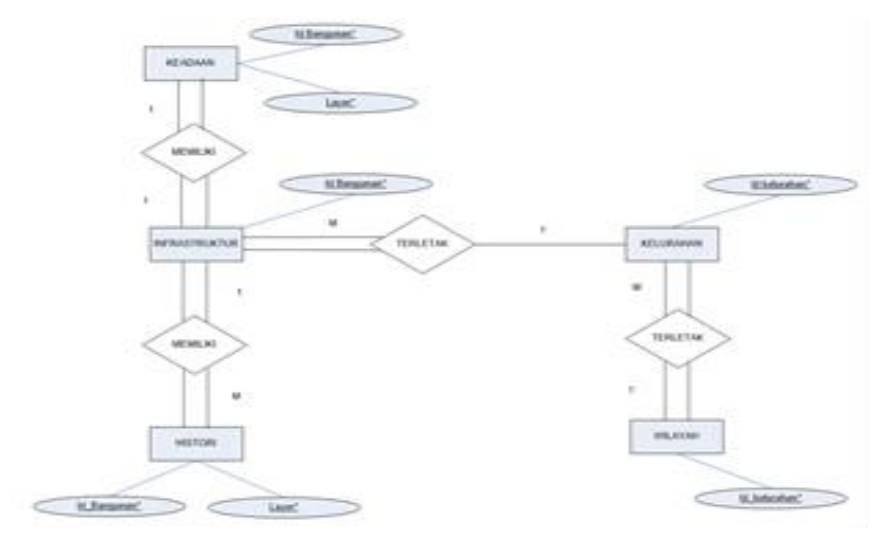

Gambar 2. ERD Sistem Informasi Infrastruktur Pemerintahan Kota Pontianak 

berikut.

Hubungan antara tabel-tabel data tabular dalam sistem informasi geografis ini dapat dilihat pada gambar 3

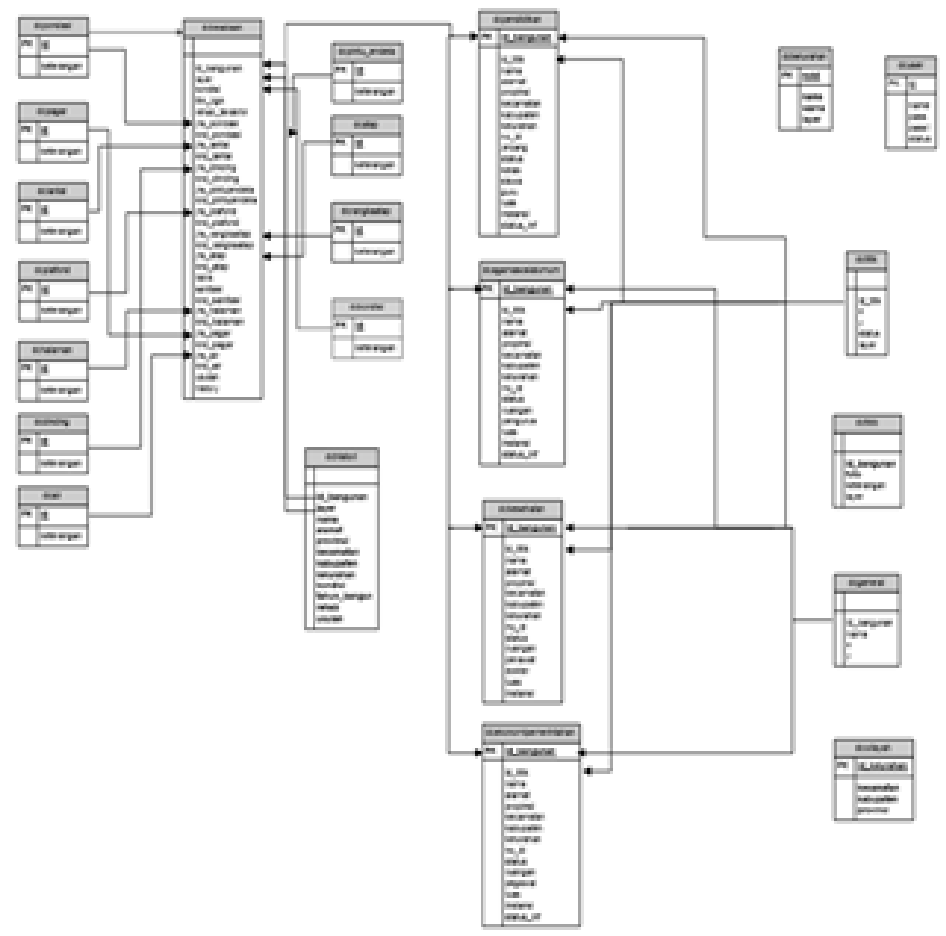

Gambar 3. Hubungan Relasi Antar Tabel Sistem Informasi Geografis Infrastruktur Pemerintahan Kota Pontianak

Pada sistem informasi geografis, data-data spasial dapat digabungkan dengan data-data tabularnya. Proses penggabungan data, yang pada sistem ini menggunakan fungsi AddRelate, memerlukan field penghubung pada masingmasing data, baik spasial maupun tabular. Data tabular yang dihubungkan dengan data spasial harus berupa tabel, dan tidak dapat berupa hasil query. Satu proses penggabungan data hanya dapat melibatkan satu layer data spasial dengan satu tabel data tabular. Setelah data-data digabungkan, data tersebut dapat di-filter berdasarkan field pada data spasial maupun field pada data tabular. Proses filter, yang pada sistem ini menggunakan fungsi FilterExpression, berfungsi agar hanya data-data yang diinginkan yang akan ditampilkan. Model hubungan antara data spasial dan data tabular dalam sistem informasi geografis ini dapat dilihat pada gambar 4 berikut.

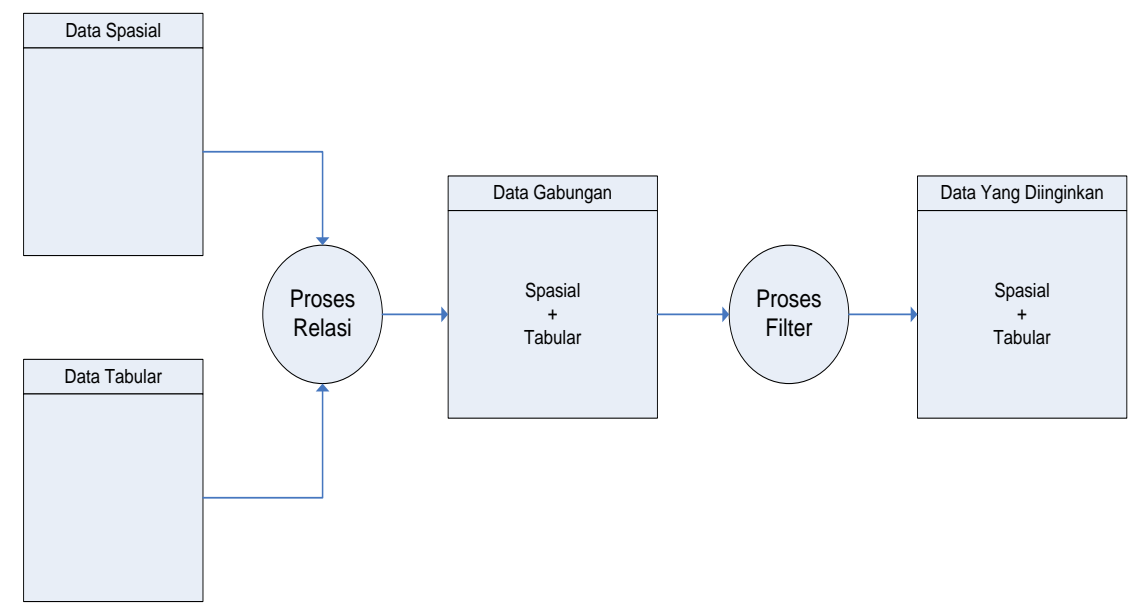

Gambar 4. Hubungan Antara Data Spasial dan Tabular Sistem 
Diagram konteks adalah diagram yang memberikan gambaran umum terhadap kegiatan yang berlangsung dalam sistem. Gambar 5 berikut ini menunjukkan diagram konteks dari sistem informasi geografis infrastruktur pemerintahan.

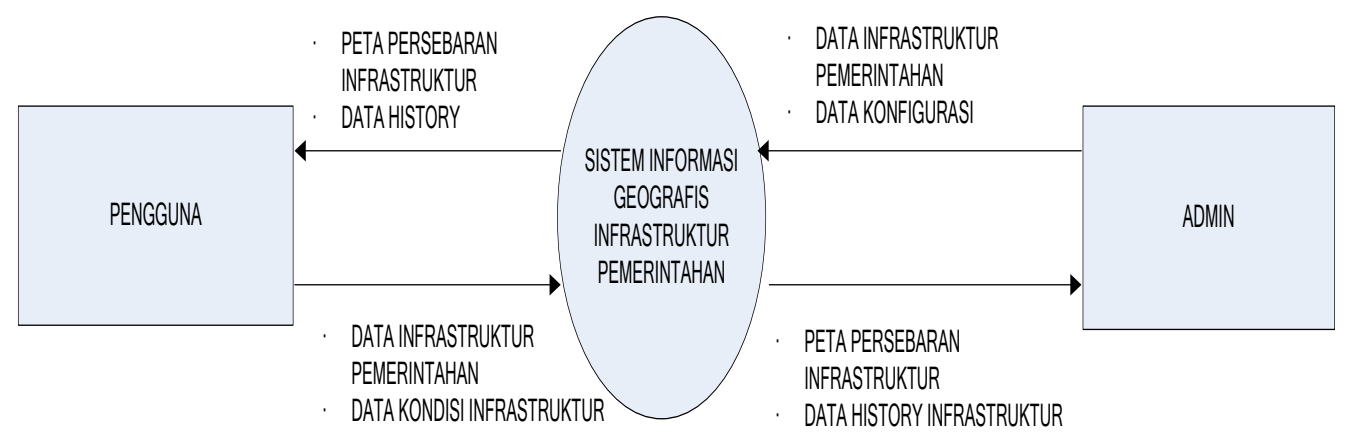

Gambar 5. Diagram Konteks Sistem Informasi Geografis

Diagram overview adalah diagram yang menjelaskan urutan-urutan proses dari diagram konteks. Pada diagram ini proses/tahapan dibagi menjadi lima proses, yaitu sebagai berikut.

1. Proses 1.0 Manajemen Peta adalah proses pengelolaan peta infrastruktur.

2. Proses 2.0 Konfigurasi merupakan proses konfigurasi pengguna, jenis bahan bangunan, dan data titiki.

3. Proses 3.0 Manajemen Data Infrastruktur adalah proses yang menampilkan pengelolaan data infrastruktur dan histori infrastruktur.

4. Proses 4.0 Login adalah proses autentifikasi untuk masuk kedalam sistem Gambar 6 menjelaskan diagram overview sistem.

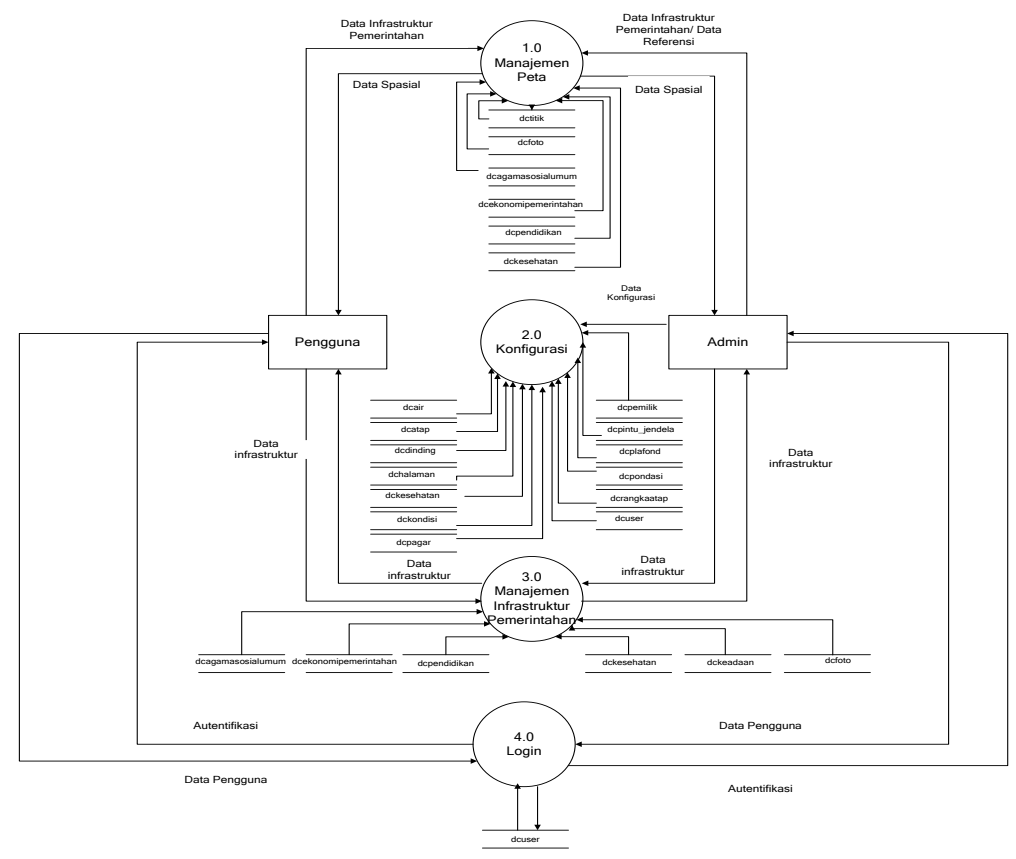

Gambar 6. Diagram Overview Sistem 
Diagram rinci ini menjelaskan lebih lanjut mengenai proses dari diagram overview, yang memperlihatkan arus data masuk dan arus data keluar.

Proses 1.0 Manajemen Peta. Proses ini terbagi lagi menjadi 6 proses sebagai berikut.

1. Proses 1.1 Tampilkan Peta

Proses ini menampilkan peta yang terdiri dari beberapa layer, yaitu sungai, kecamatan, kelurahan, jalan, kesehatan, pendidikan, agama, social, ekonomi, pemerintahan, dan umum.

2. Proses 1.2 Simpan Titik

Pada proses ini, petugas dapat menambahkan titik baru yang merepresentasikan infrastruktur, dan merelasikan titik tersebut dengan data yang sesuai pada tabel dcpendidikan, dcagamasosialumum, dcekonomipemerntahan, dan dckesehatan.

3. Proses 1.3 Identifikasi

Melalui proses ini, petugas dapat mengetahui informasi tabular dan data historis berdasarkan titik infrastruktur yang direpresentasikan oleh suatu titik pada peta.

4. Proses 1.4 Hapus Titik

Pada proses ini, petugas dapat menghapus titik yang sudah ada pada peta. Ketika petugas menghapus sebuah titik, relasi titik tersebut dengan data pada tabel dcpendidikan, dcagamasosialumum, dcekonomipemerintahan, dckesehatan, dan dctitik.

5. Proses 1.5 Pencarian Objek

Pada proses ini, petugas dapat mencari objek tertentu pada peta, seperti kecamatan, kelurahan dan jalan.

6. Proses 1.6 Tambah Peta

Pada proses ini, admin dan operator dapat menambah peta kelurahan, kemudian data kelurahan tersebut akan dimasukkan ke tabel dckelurahan.

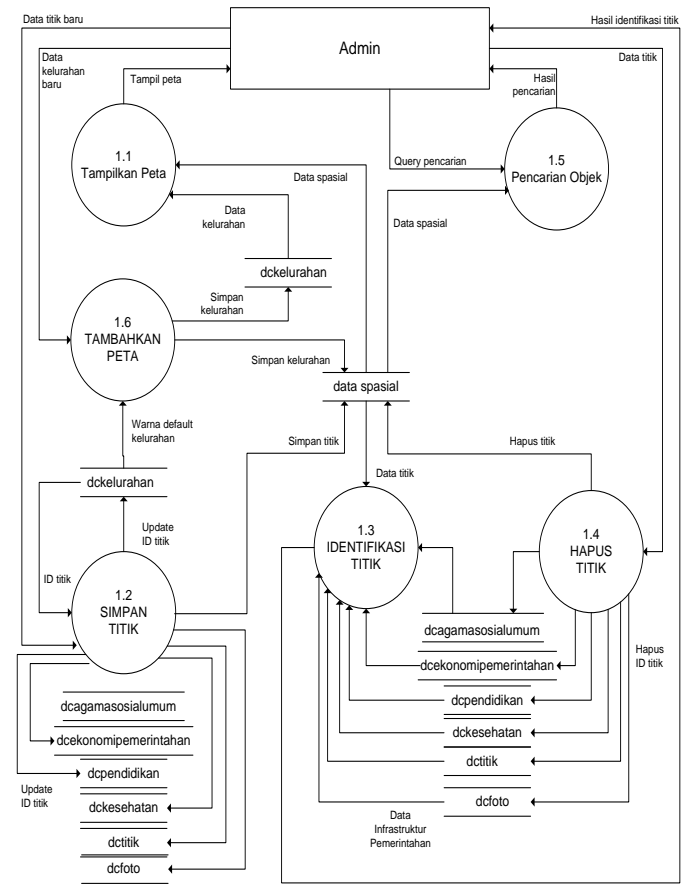

Gambar 7. Diagram Rinci Level 1.0

Proses 2.0 Manajemen Data Konfigurasi. Proses ini terbagi lagi menjadi 5 proses sebagai berikut.

1. Proses 2.1 Manajemen Data Standar

Proses ini memasukkan data standar kondisi bangunan yang dimana data ini berguna untuk pengisian data kondisi infrastruktur yang berkaitan.

2. Proses 2.2 Manajemen Data Pengguna 
Proses ini memasukkan data pengguna yang akan menggunakan sistem ini, data ini digunakan untuk validasi login di form login.

3. Proses 2.3 Manajemen Data Pemilik

Proses ini memasukkan data pemilimdari infrastruktur yang terkait, data ini berguna untuk untuk memasukkan data pemilim yang ada di form data infrastruktur.

4. Proses 2.4 Manajemen Data Bahan Bangunan

Proses ini memasukkan data bahan bangunan yang meliputi atap, dinding, halaman, pagar, pintu/jendela, plafond, pondasi dan rangka atap.

5. Proses 2.5 Manajemen Data Kelurahan

Proses ini memasukkan data kelurahan yang akan ditampilkan pada peta sesuai dengan warna yang dimasukkan.

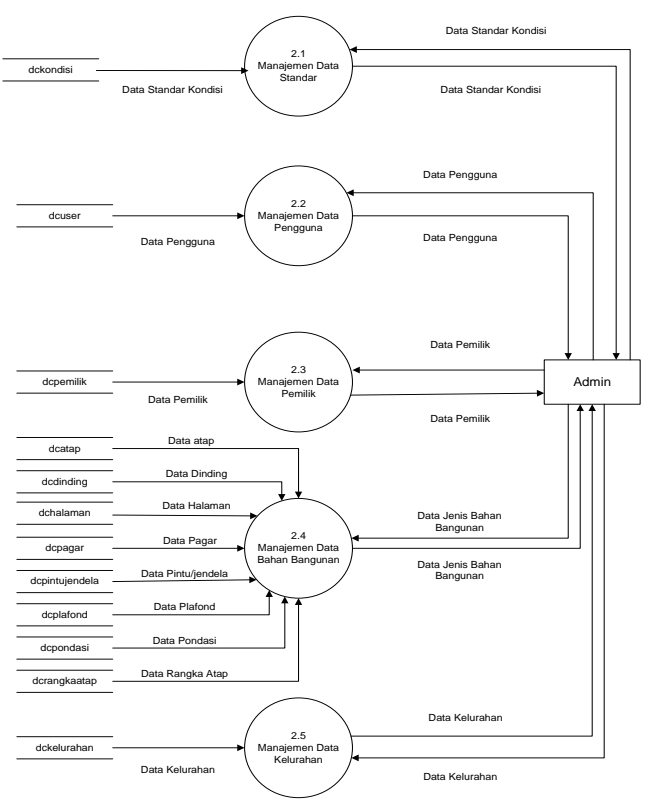

Gambar 8. Diagram Rinci Level 2.0

Proses 3.0 Manajemen Data Jenis Bahan Bangunan Proses ini terbagi lagi menjadi 5 proses sebagai berikut.

1. Proses 3.1 Tampilkan Data

Proses ini menampilkan data Infrastruktur yang dimana data diisi pada form data infrastruktur.

2. Proses 3.2 Tambah Data

Proses ini menambah data Infrastruktur yang dimana data diisi pada form data infrastruktur.

3. Proses 3.3 Ubah Data

Proses ini mengubah data Infrastruktur yang dimana data diubah pada form data infrastruktur.

4. Proses 3.4 Hapus Data

Proses ini menghapus data Infrastruktur yang dimana data dihapus pada form data infrastruktur.

5. Proses 3.5 Pencarian Data

Proses ini pencarian data Infrastruktur yang dimana data hasil pencarian pada form data infrastruktur. 


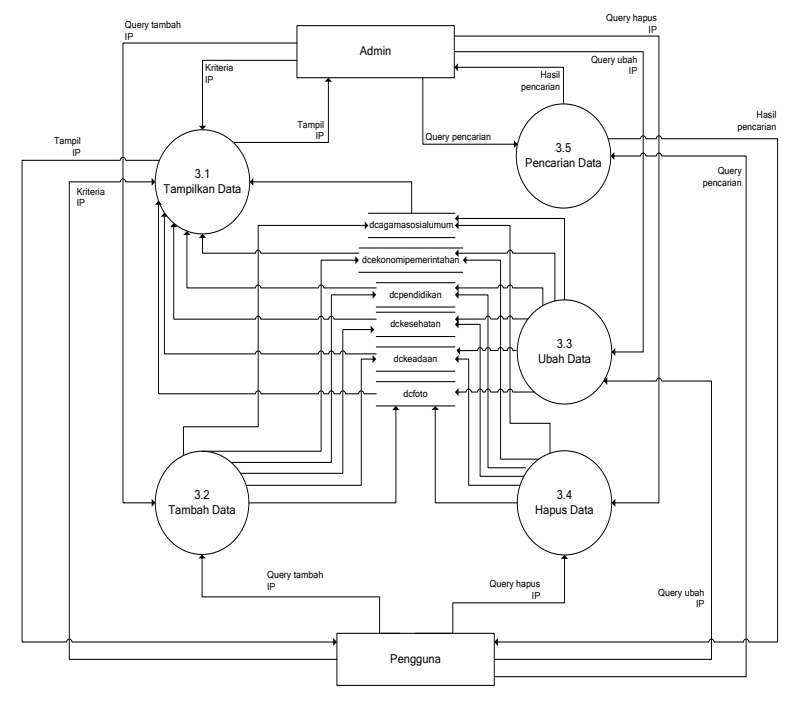

Gambar 9. Diagram Rinci Level 3.0

Antarmuka aplikasi dirancang dengan perangkat lunak Delphi. Antarmuka aplikasi dirancang dalam bentuk form dimana setiap form memiliki fungsi yang berbeda. Setiap form berisi komponen-komponen yang memperjelas struktur antarmuka aplikasi.

1. Form Login

Form ini berisi halaman login untuk menuju ke halaman utama.

2. Form Halaman Utama

Form ini digunakan untuk manajemen peta. Pada form ini petugas dapat melihat tampilan peta, menyimpan titik, meng-identifikasi titik, menghapus titik, maupun mencari kecamatan, kelurahan dan jalan pada peta. Pengguna dapat mengakses form-form lain melalui menu pada form ini.

3. Referensi

Menu ini terdiri dari tiga submenu, yaitu referensi data pemilik yang digunakan untuk memanajemen data pemilik dan referensi pengguna yang digunakan untuk memanajemen data pengguna serta referensi data standar kondisi bangunan yang digunakan untuk memanajemen data standar kondisi bangunan dan data jenis bahan bangunan yang digunakan untuk memanajemen data bahan yang digunakan untuk mendirikan infrastruktur yang terkait.

4. Data Kelurahan

Menu ini digunakan untuk memanajemn data kelurahan.

5. Data Infrastruktur

Menu ini digunakan untuk mengelola data-data Infrastruktur.

6. Pasang Titik infrastruktur

Menu ini digunakan untuk menitik titik infrastruktur yang diperoleh berdasarkan titik GPS.

Adapun struktur antarmuka sistem seperti pada gambar 10 adalah sebagai berikut.

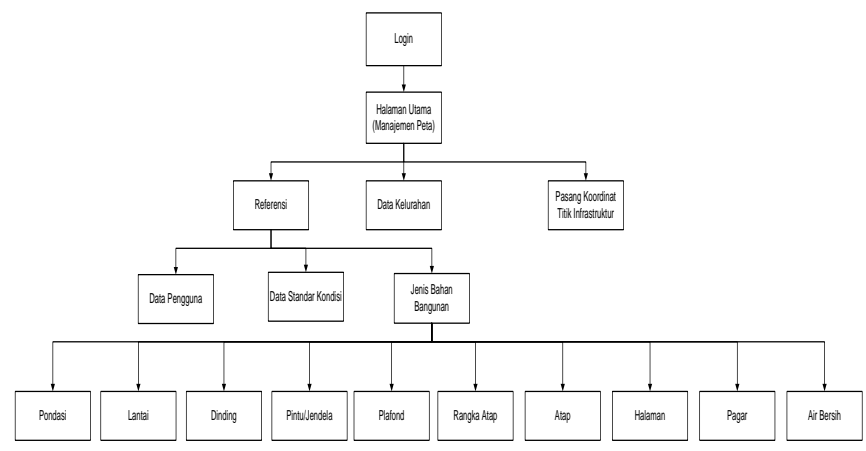

Gambar 10. Konsep Desain Antarmuka Sistem Informasi geografis 
Konsep client-server pada aplikasi dirnacang agar titik bangunan infrastruktur pada masing-masing client berjumlah sama sehingga data antar client berjumlah sama. Adapun konsep perancangan fitur client adalah sebagai berikut.

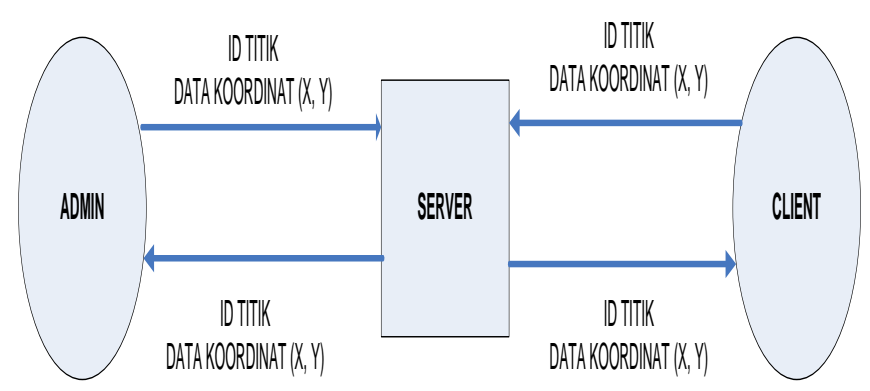

Gambar 11. Konsep Sistem Client-Server pada Sistem Informasi Geografis

\section{Simpulan}

Setelah dilakukan analisis dan pengujian terhadap Sistem Informasi Geografis Pemetaan Infrastruktur Pemerintahan, dapat disimpulkan beberapa hal sebagai berikut.

1. Sistem yang akan dirancang dapat menangani proses input data dan proses pencarian data infrastruktur serta melakukan fungsi-fungsi spasial dengan baik. Input data oleh pengguna selalu divalidasi dan ada umpan balik berupa peringatan-peringatan kepada petugas ketika terjadi kesalahan.

2. Sistem yang akan dirancang mampu menangani data histori infrastruktur serta menampilkannya dalam bentuk data atribut seperti kondisi infrastruktur, tahun pendirian infrastruktur dan tahun rehab terakhir infrastruktur.

3. Sistem yang akan dirancang dapat menunjukkan penyebaran Infrastruktur di Kota Pontianak yang digambarkan dalam bentuk peta sehingga Pengguna dapat mengetahui secara lebih jelas letak lokasi infrastruktur yang ada.

4. Sistem yang akan dirancang dapat membantu pengguna dalam menganalisis data histori sehingga dapat membantu memberikan data kerusakan yang dialami oleh infrastruktur yang ada.

5. Sistem ini dapat menjadi solusi alternatif bagi Pemerintah Kota Pontianak dan pihak-pihak terkait untuk mendukung perencanaan pemeliharaan infrastruktur daerah Kota Pontianak.

\section{Daftar Pustaka}

Dulbahri. (1993). Sistem Informasi Geografis. Gramedia: Jakarta.

Pontianak Post. (2008). Perawatan Tak Berkala, Umur Gedung Pendek. http://arsip.pontianakpost.com/berita/index.asp?Berita=Kota\&id=152569. Desember 12, 2009.

Prahasta, Eddy. (2002). Konsep-Konsep Dasar Sistem Informasi Geografis. Bandung: Informatika.

Undang-Undang Republik Indonesia No.22 Th. 1999 tentang Pemerintahan Daerah. 